\title{
ON THE INTERPRETATION OF SPEECH ACTS OF NEGATION IN ENGLISH AND BULGARIAN SPOKEN DISCOURSE
}

\author{
Deyana Peneva*
}

\begin{abstract}
The paper makes an attempt to give a more in-depth explanation of the syntactic, semantic and pragmatic aspects of a particular performative verb in English language and its translation equivalents in Bulgarian with regard to its relevance to negation and negative illocutionary attitude. The article further focuses on different scopes in negation with a view to internal and external negation markers, propositional and illocutionary characteristic features, polemic and descriptive aspects of negation. The database comprises two corpora: a set of communicative acts taken from the British national corpus (BNC) of spoken language from which all utterances represented by the performative verb reject in first person singular form were extracted and a Bulgarian corpus of data collected from 8 consecutive emissions of a current affairs talkshow Milen Tsvetkov's hour on Nova Television in which the respective verb in Bulgarian was identified. The focal point in the analysis is the interpretation of negative meanings expressed by the representative verb in both languages which vary along different context-dependent situations and propositional content.
\end{abstract}

Keywords: illocutionary force, negation, pragmatics, proposition, rejection

\section{Introduction}

In the theory of speech act phenomena and the pragmatics of illocutionary acts the category of negation has been a matter of discussion from different perspectives in that it can be considered crucial in conveying a specific semantic and pragmatic meaning. Since negation can be expressed by a variety of grammatical categories, the present paper does not deal with the syntactically negated elements in a clause but focuses primarily on a certain verb which is lexically negated, namely the performative verb reject compared to its translation equivalent in Bulgarian othvarlyam. This verb is regarded as a particular illocutionary force indicating device /IFID/ or a formulaic, routinized form which belongs to the group of commissive communicative acts (Cohen, Olshtain, Rosenstein, 1986, p. 51-73). The paper further dwells on the different types of negation relevant to the research and their quantitative and qualitative measuring in both corpora of database with respect to semantic differences and pragmatic discrepancies identified in English and Bulgarian language.

* Assist. Professor PhD at Shumen University, Department of English Studies, Shumen, Bulgaria, e-mail: d.peneva@shu.bg. 


\section{Previous research in the field}

According to linguists the semantic and pragmatic distinctions in the category of negation can be clearly shown in the disparities between the internal and external negation, propositional/illocutionary and polemic/descriptive negation. In all environments, either syntactic/adding 'not', 'no' as grammatical markers of negation/ or semantic, negation can reveal different scopes, though, not all types of negation tend to apply to communicative acts. Internal negation is regarded to be a type of negation to one or more components of a proposition whereas external is considered to affect the proposition as a whole. For example:

I have not apologized /internal/;

It is not the case I have apologized /external/

In that respect external negation has more in common with pragmatics rather than semantics as an entire clause could bear the aspect of denial, contradiction or nullification of an assertion. With a view to propositional and illocutionary negation, the former bears a close resemblance to the internal aspect of negation in that one of the components of a proposition can be negated changing the truth-values or semantic values (Moeschler, 1992, pp. 22-23). On the other hand, illocutionary negation illustrates the negation of the illocutionary force, that the speaker does not intend to perform a certain illocutionary act. For example: $I$ swear I will do it.

I swear is the illocutionary act whereas $I$ will do it refers to the propositional content. If the proposition is negated: I swear I will not do it, this represents propositional negation whilst if we negate the illocutionary act: I don't swear I will do it, illocutionary negation is apparent. In the present paper the illocutionary negation is clearly illustrated by the category of denegation, characteristic of speech act phenomena.

The last type of negation (descriptive and polemic) reveals extra nuances to the previously mentioned typologies. Descriptive negation is regarded as truthconditional, similar to propositional negation adding the aspect of a proposition containing a denial which is presupposed or expected in the context and which entails the falsity of a proposition (Blutner, 1998, pp. 115-162). By contrast, polemic negation means that the speaker objects a previous utterance and denies the acceptability of a previous communicative act (Morante, Daelemans, 2009b, pp. 28-36). For example: There are no clouds in the sky/descriptive negation/, the utterance describes a state of the world; it does not carry the meaning of the existence of a proceeding contrary presupposition. While in the case of polemic negation it bears certain aspects of illocutionary negation aiming to contrast/ contradict an adverse utterance.

In general, in the case of internal, propositional, descriptive negation the scope of negation is expressed by the sentence via the propositional content while in 
the case of external, illocutionary, polemic negation, the scope of negation is revealed by IFIDs /illocutionary force indicating devices/ which either reject, refuse, deny, contradict the propositional content. The latter is a matter of discussion and analysis in the article.

Another issue that has been explored in the paper is the commissive force of the performative verbs under examination along with a brief overview of the respective syntactic patterns they form in the utterances in both corpora.

\section{Research Questions}

In the paper, two corpora of utterances have been collected, classified and examined on the basis of their grammatical form /syntactic/, semantic content and pragmatic use extracted from BNC of spoken language (British National Corpus) and a Bulgarian corpus of communicative acts taken from 8 consecutive emissions of a current affairs talkshow Milen Tsvetkov's hour on Nova TV. In both sets of data the focus of attention has been on those utterances which contain the verb reject identified in certain syntactic frameworks and its Bulgarian translation equivalents recognized in specific grammatical patterns. Since the verb in question is performative, it is examined only in the first person singular form in the Present Simple tense. The paper aims to answer the following questions:

1) What similarities can be indicated in the semantic uses of the respective verb in English and Bulgarian?

2) What are the deviations in syntax and semantics in both sets of verbs?

3) How do Bulgarian language users differ from English native speakers in their pragmatic behaviour as determined by expressing negation regarding different contextual factors?

4) The degree of politeness which is favoured in both languages.

\section{Methods}

The linguistic material was identified, classified and explored following the Quantitative and qualitative corpus analysis (following Biber, Conrad, Reppen, 1998) with respect to the investigation of syntactic patterns and the speech acts elicitation regarding pattern preference, contextual surroundings and level of politeness. Additionally, this method of research analysis can provide material in establishing the priorities and disparities in the use of commissive utterances cross-culturally.

A number of symbolic devices and abbreviations is included in the paper:

$\mathbf{C L}$ - clause; VP - verb phrase; NP - noun phrase; V-ing - gerundial clause. 


\section{Data Analysis}

The verb reject in the English language

Reject as a full verb is mainly considered a transitive verb adding to the main verb complex an object complement. The verb reveals one basic syntactic pattern of construction (Oxford Dictionary, 2013): reject $+[\mathrm{NP}]$, though single cases of reject $+\left[\mathrm{V}_{\text {ing }}\right]$ can be identified in the database. The NP (noun phrase) is represented by a direct object which bears the semantic features /+ abstract/ in that it lacks the feature of $/+$ animate/. For example:

ex. 2016 SPOK_news ... I reject this notion that there is good 'food and bad' food...

The noun notion, in a complement combination with a demonstrative pronoun, is an abstract entity, semantically is inanimate and cannot reveal other features. In all 45 extracted utterances from reject spoken discourse in 43 syntactic patterns the predicate was followed by an abstract object, for instance:

ex. 2017 SPOK_debate ... The issue of reclaiming the word and taking ownership - I reject that entire idea.

Two sentences in the set of data reveal another pattern, that is, reject $+\left[\mathrm{V}_{\text {ing }}\right]$, in which the predicate is succeeded by a gerundial clause disclosing an activity:

ex. 2015 SPOK_talkshow ... I don't think it suits me fine. I reject going to Omaha.

With a view to the lexico-semantic meaning of the verb, the referent verb generally indicates /without being explicitly stated in addition to its literal meaning/:

the state of refusing to accept an offer, a suggestion, a proposal;

refusing to believe or use something;

refusing to hear, receive, admit /e.g. reject one's children/. (Oxford dictionary, 2013)

Since the focus of the article is to examine the commissive force of the exact verb, the last semantic meaning is excluded from analysis as it does not bear the aspect of a speaker who is reluctant or unwilling to tolerate/accept an activity or action which has been offered or uttered by another interlocutor. The speaker commits him/herself to not tolerating the action, or simply dismissing it as inadequate, unacceptable or even faulty, in that it does not correspond to the speaker's personal expectations and beliefs. In general, the speaker does not accept or agree the proposition by rejecting that the proposition should be done (Corblin, 1996, pp. 214-259). 
It should be made clear that the negative counterpart of acceptance is the state of rejecting something. In the process of examining and analysing the corpus database in all 43 reject $+\left[\mathrm{NP}_{\text {+abstract }}\right]$ structures the speakers reject either an offer or a proposal, though not a request. This is not a simple negation, in that the process or condition can be nullified or merely rendered void or logically contradictory. Additionally, in the acts of rejection, the speaker seems not to refuse to accept the truth-value conditions of the propositional content of the previous utterance or its validity or negate the existence of something, but rather rebuff a preceding communicative act which states either a proposal, offer or a suggestion. In short, a rejection can be interpreted as a type of denegation which pragmatically /with respect to its illocutionary force/ is the opposite of the acceptance of offer.

With respect to politeness, in 37 out of 43 reject $+\left[\mathrm{NP}_{\text {+abstract }}\right]$ utterances the contextual factors determining the speech act situation were strictly formal, either talkshow debates, cross-questioning discussions, political disputes, which underline the seriousness and timeliness of the topics and matters under consideration, primarily hard news problematic subjects. In the other six cases the debaters were participants in infotainments, which is more considered as a combination of journalism and entertainment in that the interlocutors may also be celebrities, art critics, etc., covering soft news topics. In either context the participants hardly know each other. Since the verb reject is a performative verb it explicitly shows directness and integrity expressing mostly distant politeness which could be face-threatening (Bach, 2006). In this respect it is clear that the type of politeness that becomes evident is negative, that is, the speaker's intended meaning /or implied meaning/ in performing a communicative act of rejection seems to be related to the want that their actions will not be impeded by others trying to preserve his/her self-image of respect (Ouali, 2005, p. 77).

Regarding the two reject $+\left[\mathrm{V}_{\text {ing }}\right]$ cases, it can be figured out that the pattern is not that common compared to the first syntactic structure, though it is possible. All two utterances are performed in an informal speech situation within which the participants in the discussion show familiarity and closeness shortening the social distance as being mostly of common background /sports celebrities, dance coaches, etc. The speech act of negation identified in the domain of the speech event /the exchange of utterances between the participants/ do not express strong rejection or refusal to accept the counterpart propositional attitude, but more or less aim to provoke the other party so that an element of entertainment and interest can be integrated. The register is both neutral and informal implying a contrast in quality and validity /respectability within a particular field between this type of content and true news. Both extracted communicative acts were identified in the field of infotainment TV discourse. Contrary to reject $+\left[\mathrm{NP}_{\text {+abstract }}\right]$ pattern, which displays negative politeness aspects, reject + [Ving] acts are both negative- and positive-politeness oriented, 
the latter mainly emphasizing the maintenance of a conflict-free relationship in which the other party is also respected.

Generally, the facts illustrated by the above cases are basically dependent of propositional and pragmatic content and their respective interpretations. On these terms the scope of negation clearly defines a semantic component which in itself functions as a prototypical operator of negation and in this sense can be interpreted as a rejection of a proposition attributable to a specific discourse context /the speech situation/. Pursuant to this, the propositional attitude conveyed by the verb reject, which semantically shows embedded refusal or incompatibility to accept another state of affairs, cannot be examined in isolation in the limits of a single clause but more within the boundaries that can be accommodated by the contextual factors and the surrounding illocutionary utterances. In this train of thought, if speech acts are mainly considered to convey external, illocutionary and polemic negation which extensively refer to the whole speech situation and contextual contour beyond the clause, while internal, propositional and descriptive type of negation is expressed within the scope of a simple clause (Haegeman, 1995, p. 44), we may conclude that propositional negation does not affect the illocutionary force of the utterance. In the event of grammatical negation, the latter statement is regarded true and appropriate, though in the case of lexicalized, implied negation, propositional meaning does affect the illocutionary force without discriminating the illocutionary interpretation. Propositional negation is privileged as its scope is broader than the sentence or clause and presupposes inference on the part of speaker's audience to recognize the communicative intentions of others (Ladusaw, 1996, pp. 321-341). These intentions are pragmatically inferred from contextual information and the utterance itself.

Another aspect of propositional content has been a matter of debate in recent years which raises concern and gains more supporters among scientists with reference to the overall view of propositions. In his book Propositional Content (Hanks, 2015, p. 265) Hanks defends a viewpoint of propositions as type of actions rather than types of truth-value statements, in the latter the meaning of a sentence or clause is constant regardless of the changes in grammar and illocutionary force. He expresses the idea that propositions are simple 'judgments and assertions', acts of predicating properties of objects'. To take an example: $I$ reject both of the methods of calculation submitted by Mr. ...

First, the speaker does not accept either method of calculation, he/she predicates the property of unsustainability of the two methods. Second, judging the sustainability of the methods is a mental act of predication which is an inner property, while, third, rejecting /in the case of the present research work/ the sustainability of the methods is a spoken act of predication, which is an outer property. Though some might be sceptical about this point of view, I feel 
strongly that Hanks's attitude can be crucial in exploring content-force relations and specifically contributes extensively to my belief that propositional negation can be featured in speech act performance.

The verb reject in the Bulgarian language

In the Bulgarian language the respective translation equivalent of the performative verb reject reveals different translation aspects, though all of them focus on a similar semantic meaning, namely, the act of eliminating, turning down, denying a suggestion, allegation, etc. Semantically, both verbs, reject and its Bulgarian translation othvarlyam are similar in meaning.

48 utterances were identified in the Bulgarian database. Two basic syntactic patterns become explicit: 1. othvarlyam $+[\mathrm{NP}]$ and 2. othvarlyam $+[\mathrm{CL}]$.

Turning to othvarlyam/othvarlya $+[\mathrm{NP}]$ pattern first, it is displayed in 41 cases, in ten of which the verb head complex is a combination of a modal and the performative verb itself. The modal structure becomes explicit in two subformats:

modal verb + performative verb $+[\mathrm{NP}]$

$$
\text { shte + othvarlya }+[\mathrm{NP}] \quad \text { /will }+ \text { reject }+[\mathrm{NP}] /
$$

ex. Shte othvarlya predlozhenieto na profesora otnosno promenite $v$ dogovornoto pravo. /in Eng.: I will reject the professor's suggestion regarding the alterations in Contract law./

modal verb + modal verb + performative verb $+[\mathrm{NP}]$

shte + tryabva da + othvarlya $+[\mathrm{NP}] \quad$ /will + have to + reject $+[\mathrm{NP}]$

ex. Shte tryabva da othvarlya dovodite na g-n Terziiski.

/in Eng.: I will have to reject the arguments of Mr Terziiski/

The full verb is transitive and bears the syntactic category of non-perfectiveness, which is absent in English. The verb can be coupled to a noun phrase which, like the same pattern in English language, bears the semantic feature /+ abstract/.

The disparities between the English and Bulgarian sets of data can be traced in utterances containing a modal auxiliary. The modal sheds extra light on the speaker's general intentions or illocutionary point reinforcing or lessening the level of commissiveness in the specific speech act (Morante, Sporleder, 2012, pp. 34-38). Since will as a modal provides information about the full verb that it governs, it may reveal various communicative functions. Apart from its deontic character, will can also infer dynamic aspect as the conditioning factors are internal, in that the speaker expresses his/her own willingness or ability to either accept or reject the act. In all indicated will + reject utterances the modal seems to subdue the aspect of negation/denegation of reject making the communicative act sound not that direct and straightforward, which on its part, may refer 
to a high level of politeness as the speaker tries to preserve his/her personal positive self-image. With a view to the second modal structure, the pattern is a combination of two modal elements which are not equivalent in meaning but reinforce each other. The second modal verb tryabva implies another shade of meaning which reveals an aspect of external, objective obligation which is discourse-oriented, though not so strong in intensity (Portner, 2007, pp. 351383). Both modal verbs, shte and tryabva, make the communicative act of rejection less probable and less intentional on the part of the speaker which in comparison with English database may refer to positive politeness aspects.

With regard to othvarlyam $+[\mathrm{CL}]$ syntactic structure, 7 utterances are identified in which the full verb is succeeded by an object clause denoting an activity, for example:

ex. Othvarlyam tova, koeto predlagate kato alternativa. /in Eng. I reject what you suggest as an alternative.

The clausal complement actually gives an account or explanation to the matter of a preceding propositional content that has been considered inadequate or inappropriate to be agreed upon. Whereas in the English set of data the object complement is represented only by a noun phrase limited to simply one, two or three constituents, the Bulgarians seem to feel that it is necessary to be more specific in what actually is being rejected. The economy of words in English may display a high level of one's self-confidence which does not aim to alleviate the severity of performative act, while in Bulgarian cases the account connotes the idea of some mitigating circumstances, reasons for the rejection and in 44 out of 48 excerpted utterances the act of rejection is succeeded by another speech act, mostly justifications in which the speaker provides arguments aiming at persuading the hearer that no blame can be imposed to him/her. For example:

Ex. Tryabva da othvarlya stanovishteto Vi otnosno savremeniya statut na semeystvoto v Bulgaria. Semeinite vrazki dnes sa v upadak i mladite hora vyarvat na priyatelite si poveche, otkolkoto na roditelite si.

/in Eng.: I must reject your statement regarding the status of the family in Bulgaria. Family relationships today are on the decline and young people trust their friends more than their parents/.

In the utterance above it seems that the speaker by using a modal of strong obligation adds another meaning to the performative verb, that is, he/she does not think that something is good enough or it can be considered inappropriate or unsuitable in some way.

Though the act of negation is present in its propositional and illocutionary scope, rejection force signaled by the speaker's refusal to add the propositional content to the common ground indicates that the negative counterpart /the act of denegation/ can occur only in specific context-dependent circumstances but 
not intuitively and is affected by certain conversational principles. The latter are implicated by an utterance and refer to what the speaker implies beyond the words $\mathrm{s} /$ he utters. In that respect pragmatic rejection can be restricted to rejection by implicature (Bach, 2006, pp. 45-46) and rejection of presupposition. The latter is based mainly on the coordination of the visible/factual/real linguistic text with the silent/hidden/unwritten implied/deeper meaning. In this respect the opposition rejection-presupposition contain aspects of propositional and illocutionary negation as well as polemic denegation, in that, what we have is a negative utterance which is used to object to a previous utterance; it has nothing to do with any real state of affairs as it is discourse-oriented. On the other hand, we cannot completely ignore the opposite side of polemic negation, namely, the descriptive negation. Regardless of the fact that it is considered world-oriented or referentially-oriented to a specific state of affairs, it can also have contextual or discourse aspects with respect to the fact that the use of a 'negative sentence always presupposes the contextual relevance of the positive counterpart' (Foolen, 1991, pp. 217-237).

\section{Results/Key Findings}

The issue of negation in this paper has been discussed as a truth-functional operator, a modal marker, a propositional approach, and a communicative act. It can have scope over a verbal predicate, though the topic at issue in the article focuses on lexicalized negation, which excludes any syntactic markers of negation. The findings indicate that:

- in both sets of data the performative verb requires an object complement which stands as a counter argument to a previously exposed proposition;

- while in the English data the syntactic patterns do not include any markers of modality, in the Bulgarian database they are present;

- in both corpora the performative verb reveals aspects of external as well as illocutionary and polemic scopes of negation, though there is a distinct propositional contour of negation which should not be overlooked as well;

- with respect to politeness, English speakers tend to express aspects of negative politeness, whereas Bulgarians are less prone to threaten some other's positive self-image which comes as a result of the modal auxiliaries preceding the performative verb. English speakers show a high level of directness and determination in defending their own point of view expressing less concern for the hearer while Bulgarians tend to be more sympathetic to the other party's positive face. 


\section{Conclusion and implications}

The elicitations from the present paper may contribute extensively to:

- a better understanding of the inherent negation exposed by speech act verbs in different socio-cultural environments;

- a more profound comprehension of specific syntactic patterns in a comparative analysis in the process of foreign language learning and acquisition;

- an in-depth cross-linguistic investigation between other verbs of negation, such as deny, object, refuse in contrast to their Bulgarian counterparts which may reveal additional argumentative and inferential qualities in the category of negation.

\section{References:}

Bach, K. (2006). The top 10 misconceptions about implicature. In B. Birner, \& G. Ward (Eds.), A festschrift for Larry Horn. Amsterdam: John Benjamins Publishing. 45-46.

Biber, D. \& Conrad, S. \& Reppen, R. (1998). Corpus linguistics. Investigating language structure and use. Cambridge: CUP.

Blutner, R. (1998). Lexical pragmatics, Journal of Semantics 15, 115-162.

Cohen, A. D., Olshtain, E. \& Rosenstein, D. S. (1986). Advanced EFL apologies: What remains to be learned? International Journal of the Sociology of Language, 62, 51-73.

Corblin, F. (1996). Multiple negation processing in natural language, Theoria 17. 214-259.

Foolen. A. (1991). Metalinguistic negation and pragmatic ambiguity: Some comments on a proposal by Laurence Horn. Pragmatics, 1, 217-237.

Haegeman, L. (1995). The syntax of negation, Cambridge: Cambridge University Press.

Hanks, P. (2015). Propositional content. Oxford University Press.

Ladusaw, W. (1996). Negation and polarity items. In Sh. Lappin (ed.), The handbook of contemporary semantic theory, (pp. 321-341). Oxford: Blackwell.

Moeschler, J. (1992). The pragmatic aspects of linguistic negation: Speech act, argumentation and pragmatic inference. Argumentation, 22-23.

Morante, R. \& Daelemans, W. (2009b). A metalearning approach to processing the scope of negation. Proceedings of CoNLL 2009. Boulder, CO. 28-36.

Morante, R. \& Sporleder, C. (2012). Modality and negation. Computational Linguistics, Saarland University. Germany. 34-38.

Ouali, H. (2005). Negation and negative polarity items. Berber, BLS 13, Berkeley: Berkeley Linguistic Society.

Portner, P. (2007). Imperatives and modals. Natural Language Semantics, 15, 351- 383.

Hornby, A. S. \& Turnbull, J. (2013). Oxford Advanced Learner's Dictionary $8^{\text {th }}$ edition. Kindle Edition. 